\title{
Efficient concrete increased water resistance modified with mineral and polymeric additives
}

\author{
Evgeniy Velichko*, Nikita Polkovnikov and Yuliya Sadchikova \\ Moscow State University of Civil Engineering, Yaroslavskoye shosse, 26, Moscow, 129337, Russia
}

\begin{abstract}
The article deals with issues of optimizing the composition of efficient concrete increased water resistance, reducing its cost without losing or increasing its basic properties. In recent years, the most effective method of tightness to water in the construction of buried and underground structures, as opposed to the use of bituminous and other traditional materials, is a method based on the use of concrete with increased water resistance. This type of tightness to water is called "White bath" in Europe. The essence of the technology is that the role of the impervious layer is performed directly by the concrete itself. The subject of the study is the composition of self-stressing concrete, which has a high density and fastness to water, but a high price compared to the concrete on Portland cement, which limits its wide application. The aim of the study is the development and optimization of the composition or stressing concrete with desired properties using a variety of mineral and polymeric additives to reduce the cost of the finished product while maintaining or improving the significant operational indicators.
\end{abstract}

\section{Introduction}

Process engineers face a number of tasks related to the properties and quality of concrete in modern capital construction. With the traditional device of waterproofing the contour of a building or structure below the ground level, important problems are the low tightness to water and crack resistance of the concrete itself and, as a result, the need to apply various waterproofing compositions based on oil products on its surface. As a result, there is an additional increase in the cost of construction. In contrast to the traditional method of waterproofing, one is used in which waterproofing is carried out by the concrete itself, without applying additional coating materials on it. In Western countries, this method of constructing an underground part of a structure is called the "White Bath". In the technology of this method are generally used self-stressing concrete and concretes with compensated shrinkage. Self-stressing concrete and concretes with compensated shrinkage differ primarily in self-stress energy. The use of such concretes allows to build seamless structures of great length (up to $500 \mathrm{~m}$ ) with increased crack resistance and tightness to water due to the developed special technology. The mechanism of hardening of selfstressing concrete is based on the creation of directional crystal formation in hardening

\footnotetext{
* Corresponding author: pct44@yandex.ru
} 
cement stone and thereby providing an adjustable amount of expansion that occurs in the plastic structure of the material, while under conditions of limited expansion, self-stress is developed to compensate for tensile stress [3]. The problem of such concrete is its cost, because the expanding additive (EA) based on ciment fondu has a high price. The objective of this study is to optimize the composition of self-stressing concrete with desired properties, reducing the quantity of EAs, through the use of various modifying additives, including secondary raw materials obtained from certain types of wastes from the production of metallurgy and the construction industry. It should be noted that the problems of optimizing the composition of the straining concrete, reducing its cost were partially considered by Gridchina, A.A. Titova L.A. [3,6,8]. Development of scientific ideas and recommendations obtaining of concrete with shrinkage compensated on the basis of different expanding agents instead of using a ready-expanding cements were engaged in Zvezdov A.I., Titov M.Yu. [4,5,9]. Issues of composition, structure and properties of selfstressing cements studied by Kuznetsova T. V. [10,12,13,14,15,16], Royak S. M. and G. S. Royak [17].

\section{Methods}

The object of the study is straining concrete, in which finely ground expanded blastfurnace slag and a polycarboxylate-based superplasticizer were taken as an additive. The following materials were used in experimental studies: standard polyfractional sand (GOST 6139-91), self-stressing cement with medium self-stress energy (GOST R 56727-2015), ballast of broken stone with the largest nominal grain size of $10 \mathrm{~mm}$ (GOST 8269.0-97), fine expanded blastfurnace slag. Grinding of expanded blastfurnace slag was carried out in a ball mill under three different modes in order to obtain different particle sizes in order to analyze the dependence of the packing density on their dispersity and, accordingly, select the optimal variant in the selection of parameters of the binder components. For the accuracy of the experiment, it was necessary to determine the size of the particles of cement and expanded blastfurnace slag in three different grinding modes on a laser particle size analyzer FRITSCH ANALYSETTE 22 NanoTec (measurement range from 0.01 to 2100 $\mathrm{mkm}$ ). Measurement of the density of cement and expanded blastfurnace slag was carried out using a Le Chatelier device according to the method according to GOST 30744-2001. The air permeability method on PSC was used to determine the Blaine specific surface area of the expanded blastfurnace slag. To study the properties of tensile concrete, 4 series of specimens with a size of 10x10x10 cm were manufactured, 4 pieces each. in each sample, with expanded blastfurnace slag content of $15,20,25 \%$, respectively, in samples $2,3,4$ (Table 1).

Table 1. Concrete composition, $\mathrm{kg} / \mathrm{m} 3$.

\begin{tabular}{|c|c|c|c|c|}
\hline \multirow{2}{*}{ Constituents of concrete } & \multicolumn{4}{|c|}{ Sample number } \\
\cline { 2 - 5 } & 1 & 2 & 3 & 4 \\
\hline Cement & 404 & 344 & 324 & 303 \\
\hline Water & 150 & 150 & 150 & 150 \\
\hline Ballast of broken stone & 1266 & 1266 & 1266 & 1266 \\
\hline Sand & 639 & 639 & 639 & 639 \\
\hline Expanded blastfurnace slag & - & 60 & 80 & 101 \\
\hline PCE (polycarboxylate) & 2,83 & 2,83 & 2,83 & 2,83 \\
\hline
\end{tabular}


At the age of 28 days, cubes were tested for compressive strength according to GOST 10180-2012. Then samples of 4 compositions were made (Table 1), 3 samples in each

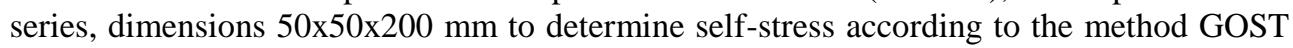
32803-2014. Maturing of the samples was carried out in special dynamometric conductors, which in the process of expansion of the concrete created an elastic restriction of deformation, equivalent to the longitudinal reinforcement of the prism samples, equal to $1 \%$. Measurements of conductors were carried out daily at the age of 1-7 days and then at the age of 10, 14 and 28 days each time with the calibration of the measuring device with the help of the standard. Then, by calculation, the self-stress value of the sample-prism Sp was determined.

Samples of cylindrical samples with a diameter of $150 \mathrm{~mm}$ and a height of $30 \mathrm{~mm}$ were also prepared with compositions similar to those used in previous tests (Table 1). According to the method of GOST 12730.5-84, the tightness to water of concrete was determined.

\section{Results}

As a result of laser analysis of the sizes of particles of cement and expanded blastfurnace slag in three different modes of grinding, the following data are presented in Table 2.

Table 2. Granulometric composition of the studied samples (sample $10 \mathrm{~g}$ ).

\begin{tabular}{|c|c|c|c|}
\hline Specimen designation & $\begin{array}{c}\text { Average particle } \\
\text { size (d50), mkm }\end{array}$ & $\begin{array}{c}\text { Maximum particle size } \\
(\mathrm{d} 98), \mathrm{mkm}\end{array}$ & $\begin{array}{c}\text { Particle content } \\
\text { less 2 mkm, \% }\end{array}$ \\
\hline $\begin{array}{c}\text { Self-stressing } \\
\text { concrete }\end{array}$ & 14,685 & 62,456 & 12,31 \\
\hline $\begin{array}{c}\text { Expanded } \\
\text { blastfurnace slag } \\
\text { initial }\end{array}$ & 11,073 & 45,022 & 14,97 \\
\hline $\begin{array}{c}\text { Expanded } \\
\text { blastfurnace slag } \\
\text { (grinding 15 min) }\end{array}$ & 10,882 & 40,878 & 14,97 \\
\hline $\begin{array}{c}\text { Expanded } \\
\text { blastfurnace slag } \\
\text { (grinding 30 min) }\end{array}$ & 9,919 & 37,119 & 16,65 \\
\hline
\end{tabular}

Also, integral and differential particle size distributions in material samples were obtained. (Figure 1,2,3,4) 


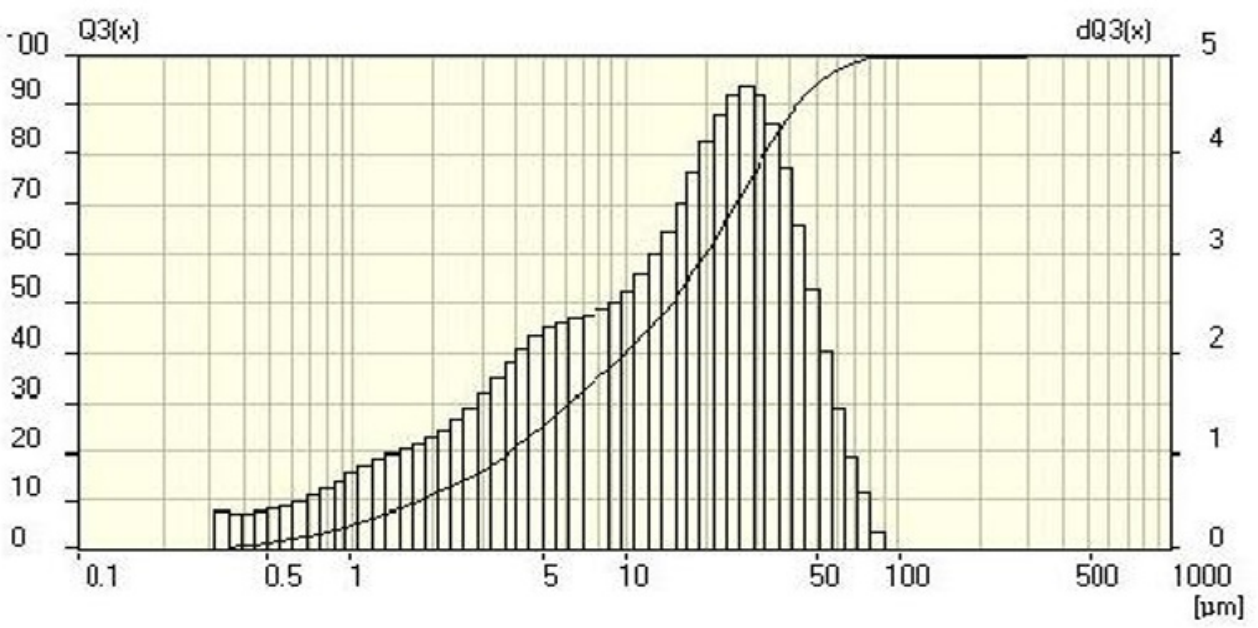

Fig. 1. Integral and differential particle size distribution of the self-stressing concrete sample.

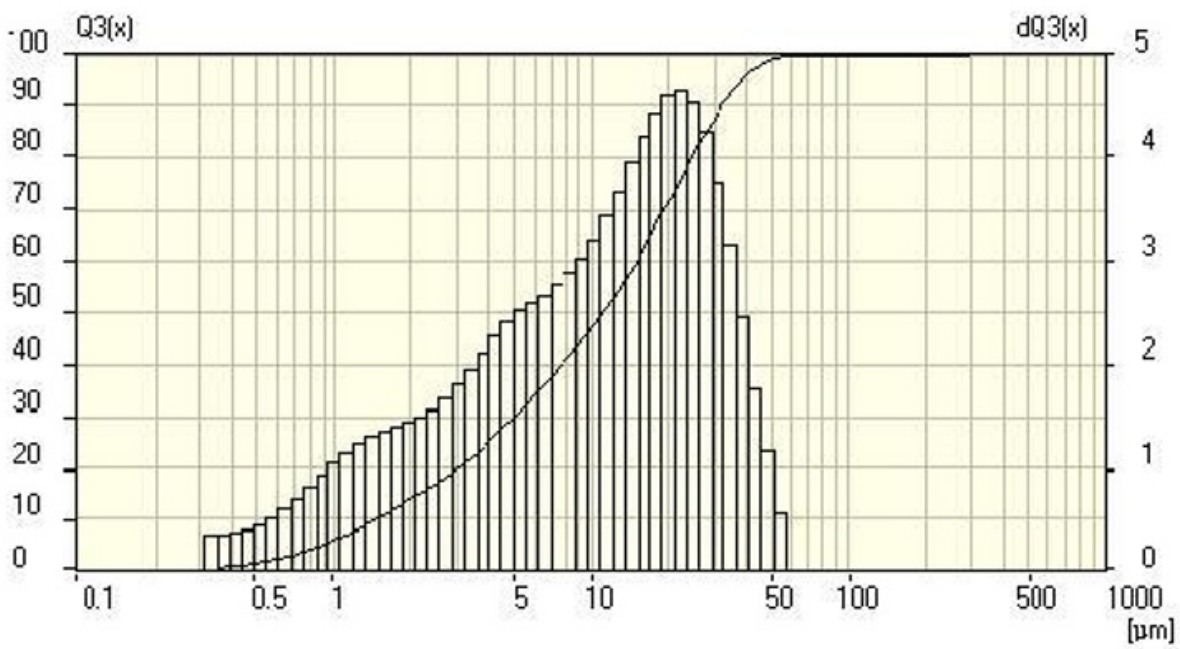

Fig. 2. Integral and differential particle size distribution of the expanded blastfurnace slag sample (initial). 


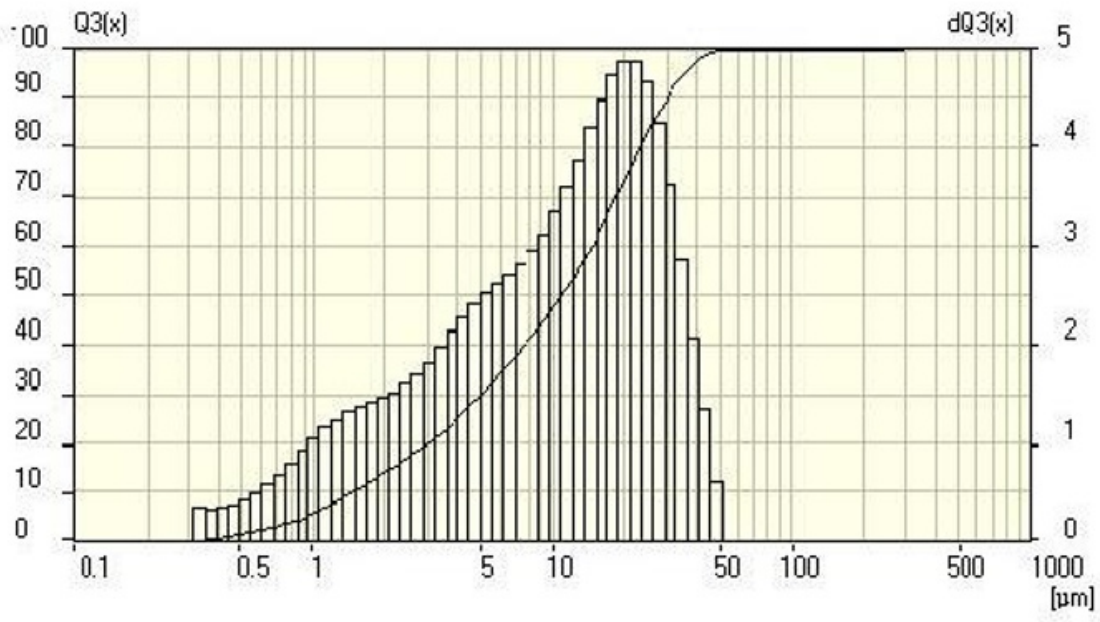

Fig. 3. Integral and differential particle size distribution of the expanded blastfurnace slag sample (grinding time $15 \mathrm{~min}$ ).

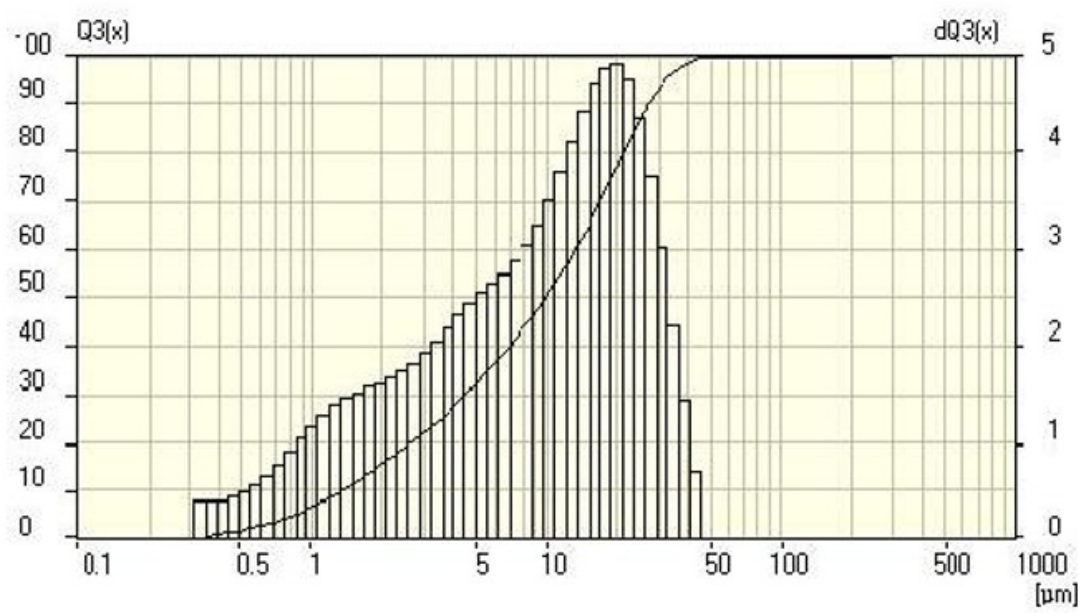

Fig. 4. Integral and differential particle size distribution of the expanded blastfurnace slag sample (grinding time $30 \mathrm{~min}$ ).

For clarity, the figure below shows a graph superimposed particle distributions or stressing cement and expanded blastfurnace slag in the initial sample (the sample) for size comparison. 


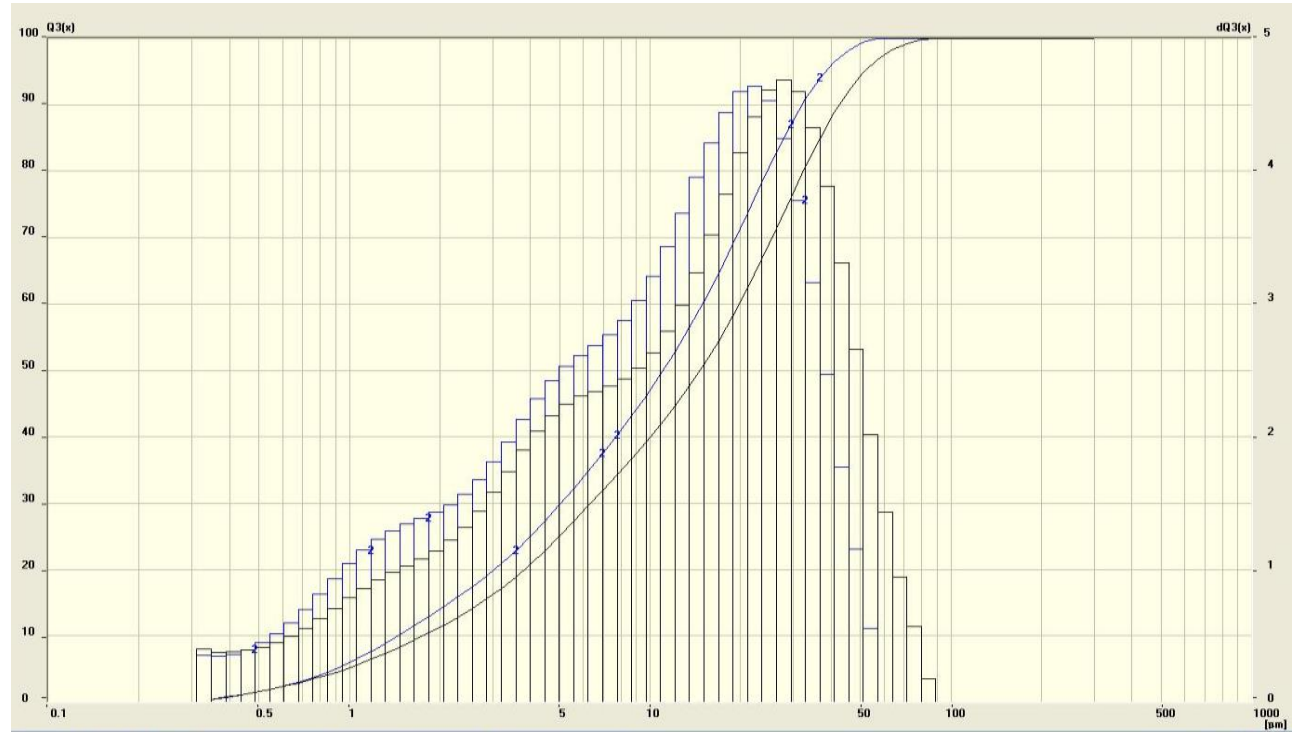

Fig. 5. The imposition of particle size distributions in NC samples (black) and expanded blastfurnace slag initial (blue).

Studies have shown that the true density of cement and expanded blastfurnace slag in the Le Chatelier flask was 2,85 и $2,66 \mathrm{~g} / \mathrm{cm}^{3}$ respectively, and the specific surface of the initial expanded blastfurnace slag was $-4685 \mathrm{~cm}^{2} / \mathrm{g}$ according to Blaine. Compressive resistance of concrete at the age of 28 days of four different compositions is presented in Table 3.

Table 3. Compression capacity of self-stressing concrete with finely dispersed expanded blastfurnace slag.

\begin{tabular}{|c|c|c|c|c|}
\hline \multirow{2}{*}{ Sample } & \multirow{2}{*}{ № } & \multirow{2}{*}{ Sample size, cm } & \multicolumn{2}{|c|}{ Compression resistance, MPa } \\
\cline { 4 - 5 } & sample & & of one sample & average value \\
\hline \multirow{3}{*}{$« 1 »$} & 1 & $9.9 \times 10 \times 9.9$ & 50.33 & \\
& 2 & $10 \times 10 \times 9.9$ & 51.91 & 51.44 \\
& 3 & $10 \times 10 \times 10$ & 52.08 & \\
& 4 & $9.8 \times 10 \times 10$ & 50.17 & \\
& 1 & $9.7 \times 10 \times 9.9$ & 51.11 & 51.76 \\
& 2 & $10 \times 9.8 \times 9.9$ & 49.94 & \\
& 3 & $10 \times 10 \times 9.9$ & 52.85 & \\
& 4 & $9.8 \times 10 \times 10$ & 51.32 & 51.78 \\
& 1 & $9.9 \times 10 \times 9.9$ & 51.55 & \\
& 2 & $10 \times 10 \times 9.9$ & 52.47 & \\
& 3 & $10 \times 9.9 \times 10$ & 51.33 & \\
& 4 & $9.8 \times 10 \times 10$ & 50.56 & \\
\hline
\end{tabular}




\begin{tabular}{|l|l|l|l|l|}
\hline & 1 & $10 \times 10 \times 10$ & 53.98 & \\
& 2 & $10 \times 9.9 \times 10$ & 52.91 & 53.03 \\
& 3 & $10 \times 10 \times 9.9$ & 52.20 & \\
\hline
\end{tabular}

As a result of processing the readings according to GOST 32803-2014 taken from dynamometric conductors, the following values of self-stress were obtained (Table 4)

Table 4. Values of self-stressing concrete with fine expanded blastfurnace slag.

\begin{tabular}{|c|c|c|c|c|}
\hline Sample & $« 1 »$ & $\ll 2 »$ & $\ll 3 »$ & $\ll 4 »$ \\
\hline $\begin{array}{c}\text { Self-stress, } \\
\text { MPa }\end{array}$ & 9,95 & 12,01 & 13,93 & 16,40 \\
\hline $\begin{array}{c}\text { Type of self- } \\
\text { stress }\end{array}$ & Sp 1,2 & Sp 1,5 & Sp 1,5 & Sp 2,0 \\
\hline
\end{tabular}

Concrete watertightness grade of 1,2 samples is W18, and 3,4 samples - W20.

\section{Discussion}

Studies show that the physical, hydrophysical and mechanical properties of tensile concrete modified with finely ground slag with a dispersion exceeding the specific surface of the cement used in combination with a polycarboxylate-based liquid polymer superplasticizer composition. An insignificant (2.9\%) increase in compression capacity was experimentally confirmed, and the self-stress of concrete with a certain dispersion of slag (samples 4) increased by 2 marks. Such an increase in self-stressing of concrete is due to the fact that expanded blastfurnace slag with a greater dispersion than that of cement is distributed mainly in interparticle voids, increasing the concentration of the solid phase per unit volume and, consequently, increasing the voltage of the entire system. At the same time there is an increase in tightness to water of concrete by 1 step.

\section{Conclusions}

It was established that with a decrease in certain limits of the content of the binder, which causes expansion or stress of the system and the replacement of its part with an active mineral additive, for example, blast-furnace slag, with greater dispersion, at which its particles are distributed mainly in interparticle voids, an increase in the concentration of the solid phase is achieved in a unit of volume and physico-mechanical properties of tensing concrete. The cost of 1 cubic meter of finished product decreases according to calculations by approximately $12 \%$.

\section{References}

1. Furmanov N 2009 Favorable composition of concrete for the manufacture of waterproof structures according to the White Bath system Engin. and Constr. 3

2. Nikitkova E V 2011 Sika waterproofing technology for underground facilities Wor. Techn. 6

3. Titova L A 2013 Straining concrete is one of the means of ensuring the reliability of the structures 85 years in the build.compl. of Mosc.and Rus. Jub. coll. of art. 171 
4. Zvezdov A I and Titov M Yu 2001 Concrete with compensated shrinkage for the erection of long-length crack-resistant structures Concr. and Ir. Concr. 4 (511)

5. Titov M Yu 2012 Concretes with increased strength based on expanding additives Build. Mat. 2

6. Titova L A and Titov M Yu 1999 Increasing the durability of concrete using expanding additives Durab. and prot. of struct. ag. cor.

7. Titova L A Beilina M I and Titov M Yu 2004 Expanding additives to increase the durability of the structure Inst.and Spec.Wor. in Constr. 1

8. Gridchina A A and Titova L A 2014 Prospects for the use of concrete on the basis of expanding additives in modern monolithic construction Theor. and ap. asp. of mod. scien. 3

9. Nesvetaev G V, Koryanova Yu I 2015 The influence of the conditions of hardening of concrete with a two-stage extension on the deformative-strength indicators Nauk. 5

10. Kuznetsova T V and Krivoborodov Yu R 2014 The composition of the properties and the use of special cements Concr. Techn. 2 8-11

11. Nesvetaev G V and Khomich L A 2014 Some properties of stressing concrete with the addition of «Embelit» Nauch.obozr. 10 642-5

12. Kuznetsova T V 1989 Aluminate and sulfoaluminate cements (Moscow: Stroyizdat) p 209

13. Kuznetsova T V 1974 Self-stressing expandable cements 6th Int. Cem. Chem. Congr.585-94

14. Kuznetsova T V 1989 Structure and properties of expanding and straining cements Res.tech. of rein.concr. struct. based on tens. cem. 8-9

15. Kuznetsova T V 1976 Physico-chemical basis of expanding cements technology Tr. NIcem. 38

16. Kuznetsova T V 1980 Chemistry and technology of expanding cements VNII-IS. Ser. 1. Cem.ind. 60

17. Royak S M and Royak G S 1983 Special cements (Moscow: Stroyizdat) p 256-9

18. Nesvetaev G V, Kolleganov A V and Ivlev L N 2008 Prospects for the use of the method of ultrasonic sounding in the examination and design of reinforcement of reinforced concrete structures Lab. Saf. In Ind. 62-6

19. Litver S L, Malinina L A, Zagurskiy V A and Panchenko A I 1985 The ratio of selfstress and free expansion of straining concretes Concr. and rein. concr. 5 15-6

20. Samchenko S V, Zorin D A, Borisenkova I V 2012 The structure and originality of expanding cements depending on the dispersion of alumina slag and sulfoaluminate clinker Techn.bet.11-12 28-30 